\title{
PENGARUH RASIO AGREGAT BINDER TERHADAP PERILAKU MEKANIK BETON GEOPOLIMER DENGAN CAMPURAN ABU SEKAM PADI DAN ABU AMPAS TEBU
}

\author{
Muliadi $^{1}$, Burhanuddin ${ }^{2}$, Darwis $^{3}$ \\ Jurusan Teknik Sipil, Fakultas Teknik, Universitas Malikussaleh \\ email: muliadi.eng@gmail.com ${ }^{1)}$, burhanbur259@ gmail.com $^{2)}$, \\ darwisgalaxy@gmai.com ${ }^{3)}$
}

\begin{abstract}
Abstrak
Beton merupakan material yang sangat penting dan banyak digunakan untuk membangun infrastruktur. Kebutuhan akan beton meningkat sejalan dengan meningkatnya kebutuhan sarana dan prasarana dasar manusia. Oleh karena itu produksi semen sebagai bahan pengikat beton meningkat pula. Dalam proses produksi semen terjadi pelepasan karbon dioksida $\left(\mathrm{CO}_{2}\right)$ yang sangat banyak ke atmosfer yang dapat merusak lingkungan. Untuk mengatasi efek buruk tersebut maka perlu dicari material lain sebagai bahan pengganti semen. Beton geopolymer merupakan salah satu alternatif untuk mengganti beton yang menggunakan semen yang kurang ramah lingkungan. Beton geopolymer dibuat tanpa menggunakan semen sebagai bahan pengikat, dan sebagai gantinya digunakan binder. Tujuan penelitian ini untuk mengetahui dan mendapatkan nilai optimum kuat tekan dari beton geopolimer dengan berbagai variasi agregat binder menggunakan bahan dasar abu sekam padi dan abu ampas tebu. Pada penelitian ini dilakukan pengujian kuat tekan beton terhadap sejumlah benda uji berbentuk kubus $15 \times 15 \times 15 \mathrm{~cm}^{3}$ dengan variasi agregat : $90 \%, 80 \%, 70 \%, 60 \%$ terhadap binder : 10\%, 20\%, 30\%, 40\%. Berdasarkan hasil penelitian diperoleh kuat tekan pada variasi 90:10, 80:20, 70:30, 60:40, dengan kuat tekan masingmasing yaitu 1,265 Mpa, 8,104 Mpa, 13,208 Mpa, 20,024 Mpa. Trend menunjukkan bahwa semakin besar komposisi binder maka semakin besar kuat tekan yang dihasilkan. Terlihat juga bahwa kuat tekan optimum dihasilkan pada variasi $60 \%$ agregat dan $40 \%$ binder yaitu 20,024 Mpa, dan sesuai dengan kuat tekan rencana $20 \mathrm{Mpa}$.
\end{abstract}

Kata kunci: Beton Geopolymer, Agregat, Binder, Kuat Tekan

\section{Pendahuluan}

Beton adalah campuran semen portland atau sembarang semen hidrolik yang lain, agregat halus, agregat kasar dan air dengan atau tanpa menggunakan bahan tambahan (Tri Mulyono, 2004). Namun, dalam kurun waktu terakhir ini, penggunaan beton sering mendapatkan kritik terutama berasal dari kalangan yang peduli dengan lingkungan hidup. Oleh karena itu yang menjadi pusat perhatian adalah emisi gas rumah kaca yang dihasilkan dari proses kalsinasi kapur dan pembakaran pada proses produksi semen yang memerlukan suhu tinggi. Sekitar 1,5 ton bahan baku yang dibutuhkan dalam produksi setiap ton semen Portland, pada saat yang sama sekitar 1 ton karbon dioksida $\left(\mathrm{CO}_{2}\right)$ dilepaskan ke lingkungan selama produksi. Peningkatan jumlah konsentrasi gas $\mathrm{CO}_{2}$ akan berakibat terhadap efek pemanasan global. Salah satu cara usaha yang dilakukan untuk mengurangi konsumsi semen adalah meningkatkan penggunaan pozzolan non semen sebagai bahan pengganti sebagian semen pada pembentukan beton semen Portland. Pozzolan adalah bahan yang mengandung silika dan alumina yang tidak mempunyai sifat pengikat seperti semen tetapi dalam bentuk yang halus dan dengan

Pengaruh Rasio Agregat Binder Terhadap Prilaku Mekanik Beton Geopolimer Dengan Campuran Abu Sekam Padi Dan Abu Ampas Tebu - Mulyadi, Burhanuddin, Darwis 
adanya air, senyawa-senyawa tersebut akan bereaksi dengan kalsium hidroksida $\left(\mathrm{Ca}(\mathrm{OH})_{2}\right)$ pada suhu kamar membentuk senyawa kalsium silikat hidrat ${ }_{3} \mathrm{CaO} .{ }_{2} \mathrm{SiO}_{2}$. $\left.{ }_{3} \mathrm{H}_{2} \mathrm{O}\right)$ dan kalsium hidrat $\left({ }_{2} \mathrm{SiO}_{2 .}{ }_{3} \mathrm{H}_{2} \mathrm{O}\right)$ yang bersifat seperti semen. Material-material yang bersifat pozzolan seperti abu terbang, abu cangkang kelapa sawit, abu sekam padi, abu ampas tebu, dan lain-lain.

Beton geopolimer diperkenalkan sebagai salah satu alternatif untuk mengurangi konsumsi semen pada pekerjaan beton. Beton geopolimer terbuat dari bahan limbah anorganik yang banyak mengandung silika dan alumina. Untuk mempercepat reaksi kimia pada beton geopolimer, maka perlu dilakukan pencampuran bahan silika dan alumina dengan zat aktivator alkaline yaitu $\mathrm{NaOH}$ dan $\mathrm{Na}_{2} \mathrm{SiO}_{3}$, bahan tersebut dicampur dengan agregat sehingga terbentuk beton geopolimer tanpa menggunakan semen lagi.

Abu sekam padi dan abu ampas tebu merupakan limbah anorganik yang banyak mengandung silika dan alumina. Disamping itu limbah industri abu sekam padi dan abu ampas tebu ini juga bisa merusak lingkungan. Oleh karena itu penggunaan limbah abu sekam padi dan abu ampas tebu untuk diolah kembali merupakan cara penanganan pencemaran lingkungan yang tepat. Dalam hal ini seberapa besar sifat mekanik beton geopolimer bahan dasar abu sekam padi dan abu ampas tebu. Dengan penggunaan abu sekam padi dan abu ampas tebu untuk pembuatan beton geopolimer, diharapkan dapat mengurangi dampak buruk dari pencemaran lingkungan, dan dapat menguntungkan dibidang pembangunan. Pada penelitian ini di lakukan pengujian kuat tekan beton geopolimer yang berbahan dasar abu ampas tebu dan abu sekam padi dalam bentuk benda uji berbentuk silinder $15 \mathrm{~cm} \times 15 \mathrm{~cm}$.

Tujuan dari penelitian ini adalah untuk mengetahui dan mendapatkan nilai optimum kuat tekan dari beton geopolimer dengan berbagai variasi agregat, binder menggunakan bahan dasar abu sekam padi dan abu ampas tebu.

\section{Tinjauan Kepustakaan}

\subsection{Beton Geopolimer}

Geopolimer merupakan bahan atau material yang berupa anorganik yang disintesa melalui proses polimerisasi. Terminologi geopolimer pertama kali digunakan oleh Profesor Davidovits pada tahun 1978, untuk menjelaskan tentang mineral polymer yang dihasilkan melalui geochemistry.Geopolimer adalah bentuk anorganik alumina-silika yang disintesa dari material yang banyak mengandung silika ( $\mathrm{Si}$ ) dan alumina ( $\mathrm{Al}$ ) yang berasal dari alam atau dari material hasil sampingan industri (Manuahe, R et al., 2014).

Dalam beton geopolimer, silikon dan aluminium yang ada pada material asal bereaksi dengan aktivator alkali dan membentuk geopolimer gel. Geopolimer gel ini kemudian mengikat agregat-agregat serta material lainnya dalam campuran yang tidak bereaksi untuk membentuk beton geopolimer (Wallah, S. E., 2014).

Geopolimer pada awalnya lebih dikenal berdasarkan reaksi kimia, sebagai alkaline-activated binders, dengan beberapa terminology yang sesuai dengan pengunaan material ini seperti low temperature inorganic polymer glasses, alkali-bonded ceramic, chemically bounded ceramic, atau alkali-activated ash (Sumajouw, D.M.J., dan Dapas, S.O., 2013). Davidovits meuraiakan bahwa komposisi kimia material geopolymer serupa dengan zeolit, tetapi memiliki 
mikrostruktur amorphous. Selama proses sintesa, atom Silika dan Alumina menyatu dan membentuk blok yang secara kimia memiliki struktur yang mirip batuan alam (Manuahe, $\mathrm{R}$ et al., 2014). Gambar 1 mengilustrasikan proses terbentukya geopolimer untuk berbagai aplikasi.

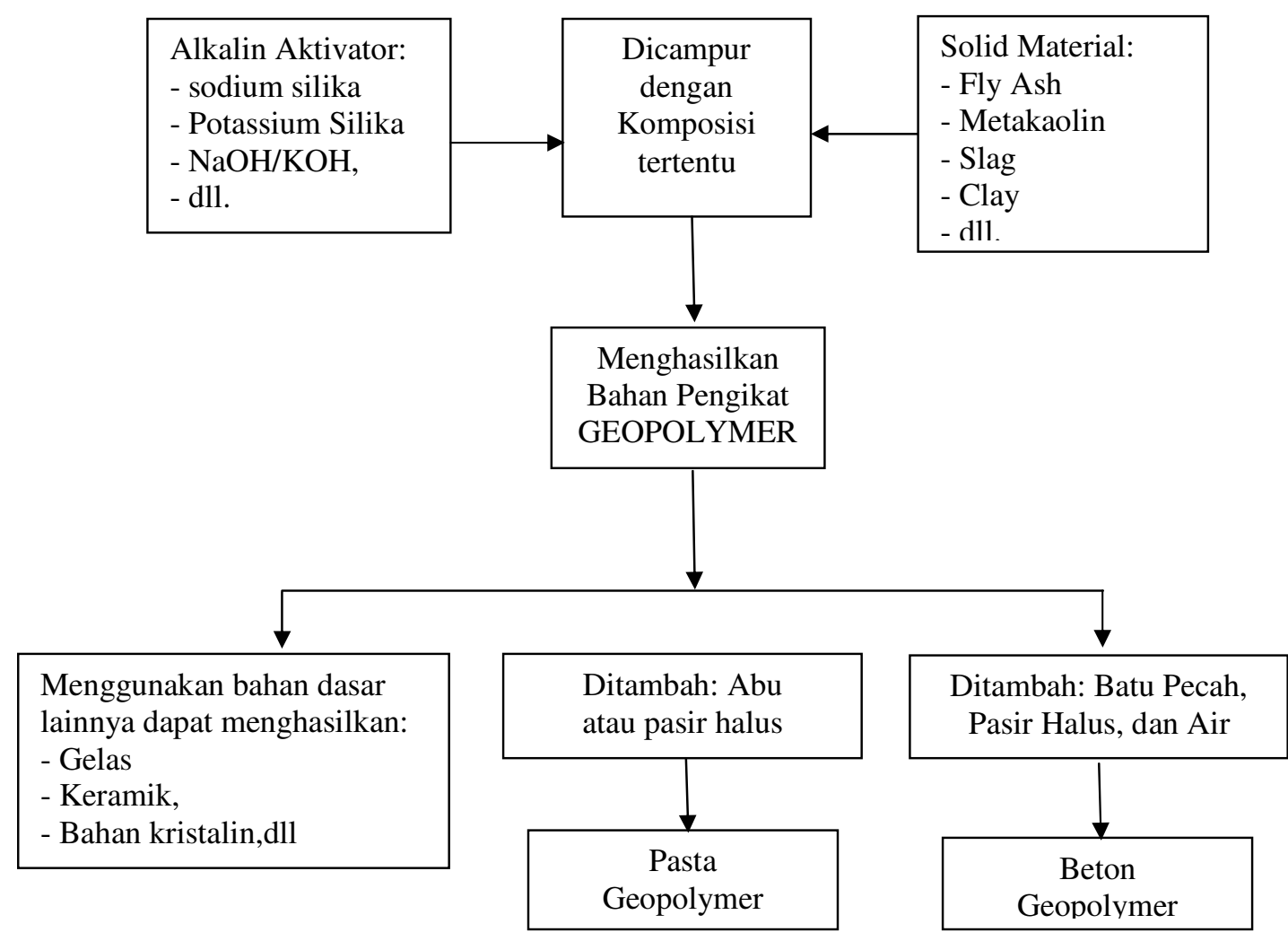

Gambar 1 Proses terbentuknya Geopolymer Sumber: Sumajouw, D.M.J., and Dapas, S.O., (2013)

\subsection{Abu sekam padi (Rice husk ash)}

Abu sekam padi merupakan bahan berligbo-selulosa seperti biomassa pada umumnya tetapi mengandung unsur silika yang sangat tinggi. Abu sekam padiyang dihasilkan dari pembakaran pada suhu $400^{\circ}-500^{\circ} \mathrm{C}$ akan menjadi silika amorphous dan apabila dibakar pada suhu lebih dari $1000^{\circ} \mathrm{C}$ akan menjadi silika kristalin. Silika amorphous yang dihasilkan diperkirakan dapat digunakan sebagai sumber penting dalam pembentukan silikon murni, karbid silikon, dan tepung nitrid silikon. Besarnya kandungan unsur silika itulah yang coba dimanfaatkan oleh peneliti untuk semakin mengoptimalkan kuat tekan beton geopolimer.

Berdasarkan penelitian yang telah dilakukan, penambahan abu sekam padi pada proporsi $10 \%$ dapat meningkatkan kuat tekan optimum. Hal tersebut dapat terjadi karena material abu sekam padi bersifat pozzolanic (Henri, BE., 2014). Komposisi kimia yang terdapat dalam abu sekam padi dapat dilihat pada Tabel 1.

Pengaruh Rasio Agregat Binder Terhadap Prilaku Mekanik Beton Geopolimer Dengan Campuran Abu Sekam Padi Dan Abu Ampas Tebu - Mulyadi, Burhanuddin, Darwis 
Tabel 1 Komposisi Kimia Abu Sekam Padi (\%)

\begin{tabular}{|c|c|}
\hline Oksida & $\begin{array}{c}\text { Kandungan } \\
(\mathbf{\%})\end{array}$ \\
\hline $\mathrm{SiO}_{2}$ & 72,28 \\
\hline $\mathrm{Al}_{2} \mathrm{O}_{3}$ & 0,37 \\
\hline $\mathrm{Fe}_{2} \mathrm{O}_{3}$ & 0,32 \\
\hline $\mathrm{CaO}$ & 0,65 \\
\hline Hilang Pijar & 21,43 \\
\hline
\end{tabular}

Sumber: Bakri., (2008)

\subsection{Abu ampas tebu (Baggase husk ash)}

Abu ampas tebu adalah abu dari hasil pembakaran ampas tebu yang diperoleh dari limbah pabrik pembuatan gula maupun dari limbah pembuatan sari tebu oleh masyarakat selanjutnya dibakar dalam drum untuk menghilangkan unsur karbon dan selanjutnya dibakar dalam furnance sampai mencapai suhu $600^{\circ} \mathrm{C}$. Penggunaan abu ampas tebu pada beton geopolimer menunjukkan peningkatan initial setting semakin lama, kuat tekan meningkat dan lebih tahan terhadap lingkungan agresif (Yusnar, C., 2013). Komposisi kimia abu ampas tebu dapat dilihat pada Tabel 2.

Tabel 2 Komposisi Abu Ampas Tebu

\begin{tabular}{|c|c|}
\hline Senyawa & Jumlah (\%) \\
\hline $\mathrm{SiO}_{2}$ & 70,97 \\
\hline $\mathrm{Al}_{2} \mathrm{O}_{3}$ & 0,33 \\
\hline $\mathrm{Fe}_{2} \mathrm{O}_{3}$ & 0,36 \\
\hline $\mathrm{K}_{2} \mathrm{O}$ & 4,82 \\
\hline $\mathrm{Na}_{2} \mathrm{O}$ & 0,43 \\
\hline $\mathrm{MgO}$ & 0,82 \\
\hline $\mathrm{C}_{5} \mathrm{H}_{8} \mathrm{O}_{4}$ & 22,27 \\
\hline
\end{tabular}

Sumber: Setya, HN dan Puspita, ID., (2011)

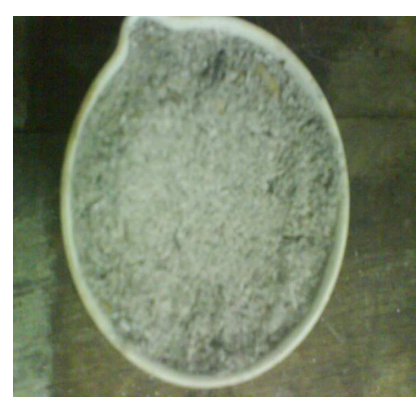

Gambar 2 Abu ampas tebu

\subsection{Alkali Aktivator}

Aktivator merupakan zat atau unsur yang menyebabkan zat atau unsur lain bereaksi. Dalam pembuatan beton geopolymer ini, aktivator yang digunakan adalah unsur alkali yang terhidrasi yaitu Sodium hidroksida $(\mathrm{NaOH})$ dan Sodium 
silikat $\left(\mathrm{Na}_{2} \mathrm{SiO}_{3}\right)$. Sodium hidroksida berfungsi untuk bisa mereaksikan unsurunsur Al dan Si yang terkandung dalam abu sekam padi dan abu ampas tebu sehingga dapat menghasilkan ikatan polimer yang kuat, sedangkan Sodium silikat mempunyai fungsi untuk mempercepat reaksi polimerisasi. Reaksi terjadi secara lebih cepat pada alkali yang banyak mengandung larutan sodium silikat dibandingkan dengan larutan alkali yang banyak mengandung larutan sodium hidroksida (Rahma,FD., 2010).

Karakteristik beton geopolymer dipengaruhi oleh parameter-parameter seperti komposisi campuran, waktu curing, agregat yang digunakan, dan lain-lain. Di dalam komposisi campuran, diantaranya terdapat kadar aktivator dan rasio alkali. Rasio alkali merupakan perbandingan antara $\mathrm{Na}_{2} \mathrm{O}$ dan $\mathrm{SiO}_{2}$. Rasio alkali diperoleh dari perhitungan perbandingan massa $\mathrm{Na}_{2} \mathrm{SiO}_{3}$ dan $\mathrm{NaOH}$ melalui persamaan reaksi kimia. Sedangkan kadar aktivator merupakan jumlah larutan alkali aktivator $\left(\mathrm{NaOH}+\mathrm{Na}_{2} \mathrm{SiO}_{3}+\right.$ air), berapa persen terhadap berat abu sekam padi dan abu ampas tebu.

\section{a. Sodium Hidroksida(NaOH)}

Sodium hidroksida $(\mathrm{NaOH})$, juga dikenal sebagai sodakaustik atau natrium hidroksida, adalah sejenis basa logam kaustik. Sodium hidroksida membentuk larutan alkalin yang kuat ketika dilarutkan ke dalam air. Digunakan di berbagai macam bidang industri, kebanyakan digunakan sebagai basa dalam proses produksi bubur kayu dan kertas, tekstil, air minum,sabun dan deterjen. Sodium hidroksida adalah basa yang paling umum digunakan dalam laboratorium kimia (Veliyati, 2010).

Sodium hidroksida $(\mathrm{NaOH})$ berfungsi untuk dapat mereaksikan unsur-unsur Al dan Si yang terkandung di dalam abu sekam padi dan abu ampas tebu sehingga dapat menghasilkan ikatan polimer yang kuat. Sodium hidroksida yang tersedia umumnya berupa serpihan dengan kadar $98 \%$. Sebagai aktivator, Sodium hidroksida harus dilarutkan terlebih dahulu dengan air sesuai dengan molaritas yang diinginkan. Larutan ini harus dibuat dan didiamkan setidaknya selama satu malam sebelum pemakaian (Rahma,FD., 2010).

\section{b. Sodium silikat $\left(\mathrm{Na}_{2} \mathrm{SiO}_{3}\right)$}

Sodium silikat merupakan salah satu bahan tertua dan paling aman yang sering digunakan dalam industri kimia. Karena proses produksinya lebih sederhana maka sejak 1818, sodium silikat berkembang dengan cepat. Sodium silikat dapat dibuat dengan 2 proses, yaitu proses kering dan proses basah. Pada proses kering, pasir $\left(\mathrm{SiO}_{2}\right)$ dicampur dengan sodium carbonate $\left(\mathrm{Na}_{2} \mathrm{CO}_{3}\right)$ atau dengan potassium carbonate $\left(\mathrm{K}_{2} \mathrm{CO}_{3}\right)$ pada temperatur $1100-1200^{\circ} \mathrm{C}$. Hasil reaksi tersebut menghasilkan kaca (cullets) yang dilarutkan ke dalam air dengan tekanan tinggi menjadi cairan yang bening dan agak kental. Sedangkan pada proses basah, pasir $\left(\mathrm{SiO}_{2}\right)$ dicampur dengan sodium hidroxide $(\mathrm{NaOH})$ melalui proses filtrasi danakan menghasilkan sodium silikat yang murni (Veliyati, 2010).

Sodium silikat terdapat dalam 2 bentuk, yaitu padatan dan larutan dimana untuk campuran beton lebih banyak digunakan dengan bentuk larutan. Sodium silikat atau yang lebih dikenal dengan water glass, pada mulanya digunakan

Pengaruh Rasio Agregat Binder Terhadap Prilaku Mekanik Beton Geopolimer Dengan Campuran Abu Sekam Padi Dan Abu Ampas Tebu - Mulyadi, Burhanuddin, Darwis 
sebagai campuran dalam pembuatan sabun. Tetapi dalam perkembangannya, sodium silikat dapat digunakan untuk berbagai macam keperluan, antara lain untuk bahan campuran semen, pengikat keramik, coating, campuran cat serta dalam beberapa keperluan industri, seperti kertas, tekstil dan serat. Beberapa penelitian telah membuktikan bahwa Sodium silikat dapat digunakan untuk bahan campuran dalam beton (Rahma FD, 2010).

\subsection{Kuat Tekan}

Kuat tekan merupakan tingkat atau derajat kekuatan suatu material terhadap gaya tekan dari luar yang membebaninya. Kuat tekan dapat dirumuskan sebagai berikut:

dengan:

$$
\mathrm{f}^{\prime} \mathrm{c}=\frac{p_{m a}}{A}
$$

f'c = kuat tekan beton $(\mathrm{MPa})$

Pmaks = beban tekan maksimum $(\mathrm{N})$

A $\quad=$ luas permukaan benda uji tertekan $\left(\mathrm{mm}^{2}\right)$

Pengujian kuat tekan beton menggunakan alat uji kuat tekan Universal Testing Machine, seperti diperlihatkan pada gambar 3.

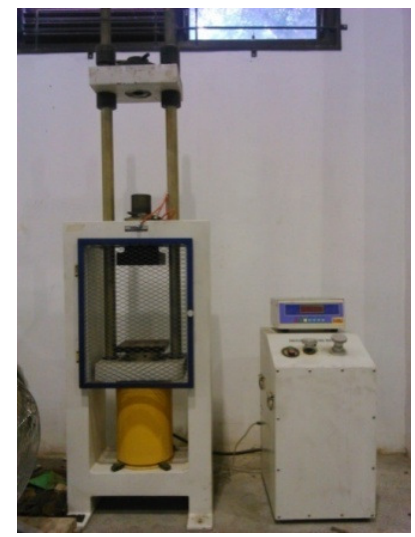

\section{Gambar 3 Alat Uji Kuat Tekan Beton}

Faktor-faktor yang mempengaruhi besarnya kuat tekan antara lain:

1. Proporsi bahan-bahan penyusun

Di dalam komposisi campuran beton geopolimer terdapat agregat, air, bender molaritas $\mathrm{NaOH}$, modulus alkali, kadar aktivator, faktor air binder, dan lainlain. Proporsi bahan-bahan penyusun ditentukan melalui mix design.

2. Metode perancangan (mix design)

Standar perancangan bahan susun beton geopolimer belum ada sampai saat ini, sehingga dibutuhkan metode pendekatan, salah satunya dapat digunakan perancangan beton konvensional, yang dihitung berdasarkan SK- SNI 032834-2002. Prinsip utama dalam perancangan campuran beton geopolimer yaitu penggantian pasta (semen + air) dengan (prekursor + aktifator + air), sedangkan untuk kebutuhan agregat kasar dan kerikil sama seperti kebutuhan agregat beton konvensional.

Pengaruh Rasio Agregat Binder Terhadap Prilaku Mekanik Beton Geopolimer Dengan Campuran Abu Sekam Padi Dan Abu Ampas Tebu - Mulyadi, Burhanuddin, Darwis 
3. Perawatan (curing)

Perawatan berfungsi untuk menghindari panas hidrasi yang tidak diinginkan, terutama yang disebabkan oleh suhu. Sifat beton yang akan dihasilkan, terutama dari segi kekuatannya, ditentukan oleh alat dan bahan yang digunakan pada proses curing.

\section{Metode Penelitian}

\subsection{Data primer}

Data primer merupakan data yang dikumpulkan langsung dari hasil kuesioner, wawancara, ataupun observasi dan bukan berasal dari data yang sudah pernah dilakukan sebelumnya (untuk data uji laboratorium). Data primer dalam penelitian ini berupa data pengujian sifat-sifat fisis material, data mix design, data slump test dan data pengujian kuat tekan beton geopolimer.

\subsection{Data sekunder}

Data sekunder adalah data yang telah tersedia sebelumnya baik dari bacaan ataupun penelitian terdahulu dan tidak langsung diperoleh dari subjek penelitian. Data sekunder dalam penelitian ini berupa gradasi agregat, komposisi beton, kadar air bebas, gradasi agregat halus, dan nilai slump yang disyaratkan.

\subsection{Analisis dan Pengolahan Data}

Analisis data dalam penelitian ini dimulai dengan pemeriksaan sifat-sifat fisis agregat yang digunakan untuk pembuatan benda uji yaitu meliputi berat jenis, absorbsi, berat volume, analisa saringan, dan kadar air yang dikandung, selanjutnya dilakukan perencanaan campuran beton (mix design), yaitu mencampur agregat, abu sekam padi dan abu ampas tebu dengan mixer concrete. Apabila campuran tersebut tercampur dengan sempurna dilanjutkan penambahan alkali aktivator dan air yang telah didiamkan selama 24 jam, kemudian dituangkan kedalam cetakan betonyang berbentuk silinder. Lalu dilakukan proses pemadatan untuk masing-masing benda uji dengan menusuk-nusuk batang besi ke dalam adukan yang sudah dimasukkan ke dalam cetakan beton yang berbentuk silinder tersebutdan dipukul-pukul dengan menggunakan palu karet. Setelah beton geopolimer mengeras maka dilakukan perawatan selama 7 hari dan dilanjutkan dengan uji kuat tekan beton geopolimer.

\section{Hasil dan Pembahasan}

\subsection{Hasil}

Tes kuat tekan beton geopolimer ini dilakukan pada umur tujuh hari. Untuk setiap tes kuat tekan digunakan 5 (lima) benda uji .Setiap komposisi diambil nilai rata-rata dari setiap nilai yang diperoleh. Beton berbentuk kubus dengan ukuran sisi $150 \mathrm{~mm}$ dilakukan pengujian kuat tekan pada umur tujuh hari. Kuat tekan beton menggambarkan mutu dari sebuah struktur, semakin tinggi tingkat kekuatan struktur yang dicapai, maka mutu beton yang akan dihasilkan lebih tinggi. Untuk lebih jelasnya diperlihatkan pada Tabel 3.

Pengaruh Rasio Agregat Binder Terhadap Prilaku Mekanik Beton Geopolimer Dengan Campuran Abu Sekam Padi Dan Abu Ampas Tebu - Mulyadi, Burhanuddin, Darwis 
Tabel 3 Hasil Tes Kuat Tekan Rata-Rata Beton Geopolimer

\begin{tabular}{|c|c|c|c|c|c|}
\hline No & Agregat:Binder & $\begin{array}{c}\text { Kuat Tekan } \\
\text { Rencana } \\
\text { (Mpa) }\end{array}$ & $\begin{array}{c}\text { Nilai Kuat } \\
\text { Tekan } \\
(\mathrm{MPa})\end{array}$ & $\begin{array}{l}\text { Nilai Kuat } \\
\text { Tekan } \\
\text { Rata-Rata } \\
(\mathrm{MPa})\end{array}$ & $\begin{array}{l}\text { Umur } \\
\text { (Hari) }\end{array}$ \\
\hline 1 & \multirow{5}{*}{$\begin{array}{l}90 \% \text { Agregat dan } \\
10 \% \text { Binder }\end{array}$} & \multirow{5}{*}{20} & 1,30 & \multirow{5}{*}{1,256} & \multirow{5}{*}{7} \\
\hline 2 & & & 1,15 & & \\
\hline 3 & & & 1,20 & & \\
\hline 4 & & & 1,39 & & \\
\hline 5 & & & 1,24 & & \\
\hline 6 & \multirow{5}{*}{$\begin{array}{l}80 \% \text { Agregat dan } \\
20 \% \text { Binder }\end{array}$} & \multirow{5}{*}{20} & 8,15 & \multirow{5}{*}{8,104} & \multirow{5}{*}{7} \\
\hline 7 & & & 8,07 & & \\
\hline 8 & & & 8,10 & & \\
\hline 9 & & & 8 & & \\
\hline 10 & & & 8,20 & & \\
\hline 11 & \multirow{5}{*}{$\begin{array}{l}70 \% \text { Agregat dan } \\
30 \% \text { Binder }\end{array}$} & \multirow{5}{*}{20} & 13,20 & \multirow{5}{*}{13,208} & \multirow{5}{*}{7} \\
\hline 12 & & & 13,10 & & \\
\hline 13 & & & 13,21 & & \\
\hline 14 & & & 13,25 & & \\
\hline 15 & & & 13,28 & & \\
\hline 16 & \multirow{5}{*}{$\begin{array}{c}60 \% \text { Agregat dan } \\
40 \% \text { Binder }\end{array}$} & \multirow{5}{*}{20} & 20,02 & \multirow{5}{*}{20,024} & \multirow{5}{*}{7} \\
\hline 17 & & & 19,98 & & \\
\hline 18 & & & 20,04 & & \\
\hline 19 & & & 20,08 & & \\
\hline 20 & & & 20 & & \\
\hline
\end{tabular}

Berdasarkan Tabel 3, dapat dilihat bahwa hasil penelitian yang telah dilakukan memperoleh kuat tekan yang memenuhi syarat beton. Untuk persentase agregat $90 \%$ dan binder $10 \%$ diperoleh kuat tekan rata-rata sebesar 1,256 Mpa, untuk persentase 80\%: 20\% diperoleh kuat tekan rata-rata sebesar 8,104 Mpa, untuk persentase 70\%:30\% diperoleh kuat tekan rata-rata sebesar 13,208 Mpa, untuk persentase 60\%: $40 \%$ diperoleh kuat tekan rata-rata 20,024 Mpa, sehingga dapat disimpulkan bahwa semakin besar persentase binder yang digunakan pada campuran beton maka semakin tinggi kuat tekan beton yang didapat.

\subsection{Pembahasan}

Pemakaian binder dalam campuran beton dapat berpengaruh terhadap kuat tekan beton, yaitu signifikan menaikkan kuat tekan beton. Sedangkan penggunaan agregat dalam campuran beton dapat berpengaruh juga terhadap kuat tekan beton, yaitu kurang signifikan menaikkan kuat tekan beton. Hal ini dikarenakan penggunaan komposisi binder yaitu abu sekam padi dan abu ampas tebu hasil pembakaran batu bara yang banyak mengandung silika dan alumina lebih sedikit daripada penggunaan terhadap agregat yang persentase komposisi besar sehingga dapat mengurangi pengikatan antara material pada campuran beton.

Dapat disimpulkan bahwa penggunaan binder abu sekam padi dan abu ampas tebu yang digunakan pada campuran beton dapat diterima, karena kuat tekan yang dihasilkan masih memenuhi persyaratan sebagai beton normal non- 
struktural (f'c $<17,5 \mathrm{Mpa}$ ) ditinjau berdasarkan SNI 03-2847-2002. Untuk lebih jelasnya diperlihatkan pada Gambar 4.

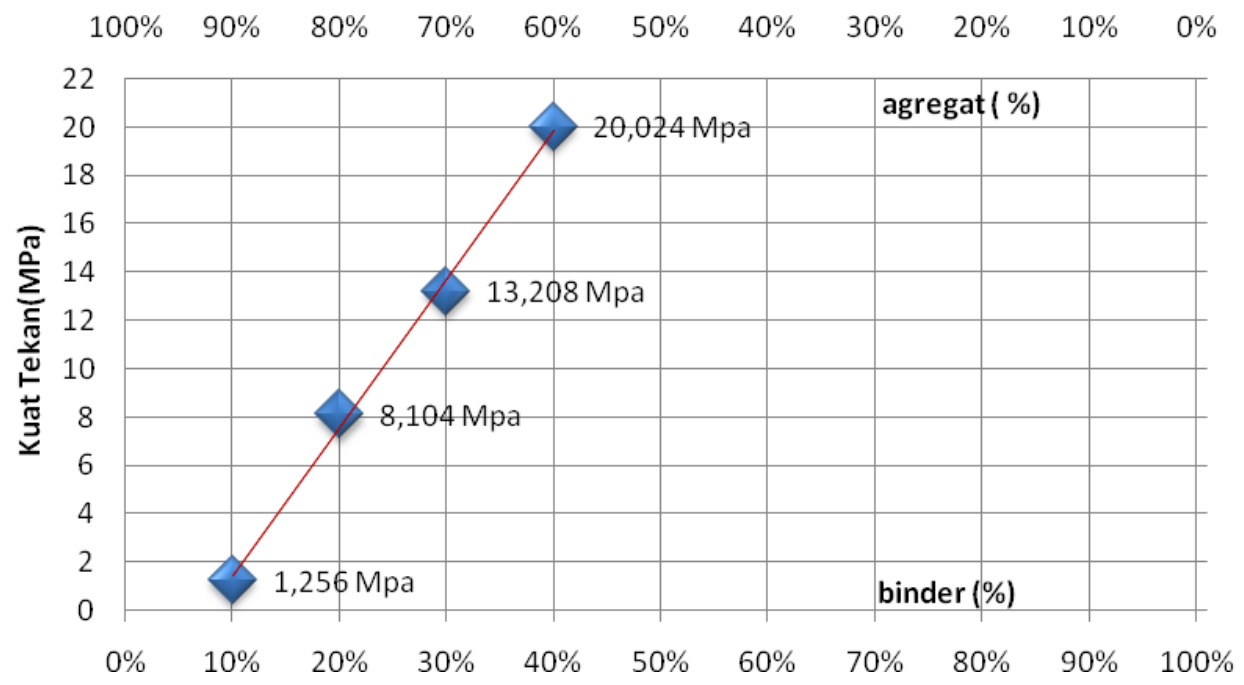

Gambar 4 Grafik tes kuat tekan beton geopolimer

Berdasarkan gambar 4 dapat dilihat bahwa pada persentase $40 \%$ binder diperoleh kuat tekan yang besar karena terkandung lebih banyak silika dan alumina activator.

\section{Kesimpulan dan Saran}

\subsection{Kesimpulan}

Dari hasil penelitian dan pembahasan yang telah dilaksanakan, diperoleh kesimpulan sebagai berikut:

1. Penggunaan binder dari limbah abu sekam padi dan abu ampas tebu dengan presentase sama 50\% sebagai binder dalam campuran beton geopolimer memberikan pengaruh pada kuat tekan beton, hal ini semakin banyak komposisi binder yang digunakan pada campuran beton maka semakin tinggi kuat tekan beton yang didapat.

2. Kedua binder dari limbah abu sekam padi dan abu ampas tebu memberikan hasil kuat tekan mencapai kuat tekan rencana $20 \mathrm{Mpa}$, yang menunjukkan bahwa campuran binder berpengaruh terhadap kuat tekan beton. Perolehan hasil menacapai kuat tekan rencana didapat pada variasi agregat 60\%: 40\% binder yaitu sebesar 20,024 Mpa.

\subsection{Saran}

Penelitian ini hanya dilakukan dengan gabungan dua limbah (limbah abu sekam padi dan abu ampas tebu) dengan presentasi sama 50\%, dengan kuat mutu rencana beton $20 \mathrm{MPa}$. Maka perlu adanya penelitian lebih komprehensif terhadap variasi mutu beton rencana dan variasi presentase campuran binder, serta variasi gabungan binder (fly ash, abu cangkang kelapa sawit dan lainya). Agar didapat kajian lebih mendalam tentang beton geopolimer.

Pengaruh Rasio Agregat Binder Terhadap Prilaku Mekanik Beton Geopolimer Dengan Campuran Abu Sekam Padi Dan Abu Ampas Tebu - Mulyadi, Burhanuddin, Darwis 


\section{Daftar Kepustakaan}

Henri, BE., 2014, Pengaruh Komposisi Solid Material Abu Terbang Dan Abu Sekam Padi Pada Beton Geopolimer Dengan Alkaline Activator Sodium Silikat Dan Sodium Hidroksida, Universitas Atma Jaya Yogyakarta, Yogyakarta.

Mulyono, T., 2004, Teknolgi Beton, Andi, Yogyakarta.

Manuahe, R et al., 2014, Kuat Tekan Beton Geopolimer Berbahan Dasar Abu Terbang (Fly ash), Jurnal Sipil Statik Vol.2 No.6, Universitas Sam Ratulangi.

Rahma, FD., 2010, Pengaruh Modulus Alkali dan Kadar Aktivator Terhadap Kuat Tekan Fly ash-Based Geopolimer mortal, Surakarta.

Setya, HN, et al, 2011, Pabrik Silika dari Abu Ampas Tebu dengan Proses Presipitasi, http://ITS-NonDegree-12882-Presentation.

Sumajouw, D.M.J., dan Dapas, S.O., 2013, Elemen Struktur Beton Bertulang Geopolimer, Andi, Yogyakarta.

Standar Nasional Indonesia, 2002, Persyaratan Gradasi Agregat Kasar Dan Agregat Halus (SNI 03-2834:2002), Badan Standardisasi Nasional, Puslitbang pemukiman, Bandung.

Standar Nasional Indonesia, 2002, Tata Cara Perhitugan Struktur Beton Untuk Bangunan Gedung, (SNI 03-2847-2002), Badan Standardisasi Nasional, Puslitbang pemukiman, Bandung.

Veliyati, 2010, Pengaruh Faktor Air Binder Terhadap Kuat Tekan Dan Workability Fly Ash Based Geopolymer Mortar, Universitas Sebelas Maret Surakarta, Surakarta.

Wallah, S. E., 2014, Pengaruh Perawatan dan Umur Terhadap Kuat Tekan Beton Geopolimer Berbasis Abu Terbang, Jurnal Ilmiah Media Engineering Vol.4 No.1, Universitas Sam Ratulangi Manado.

Yusnar, C, 2013, Karakteristik Durabilitas Beton Agropolimer Kombinasi Dengan Memanfaatkan Limbah Abu Sekam Padi, Abu Ampas Tebu dan Kapur Sebagai Bahan Alternatif Pengganti Semen, http://www.jurnal.com. 